\title{
The Impact of the Birth Year on the Company's Actual Controller Over-Investment Behavior Based on 2007-2017 A-Share-Listed Company Data
}

\author{
Qijun Wang \\ Baylor University, China \\ Jacksonwang0804@163.com
}

Key Words: The year of fate; Informal institutional arrangement; Excessive investment; Cultural phenomena

\begin{abstract}
The year of fate is a special cultural phenomenon between Chinese folk custom and religious belief in Chinese traditional culture, and culture as an informal institutional arrangement may affect the behavior of enterprises and their managers. The thesis conducts an empirical analysis on the impact of the actual controller of a listed company on the company's excessive investment behavior during the actual controller's year of fate, using LOGIT model.

The empirical results show that in private listed companies, the probability of over-investment in the actual controller's year of fate is significantly lower, whereas this relationship is insignificant in state-owned listed companies. Further, the probability of over-investment in the full sample and the sample of private listed companies is significantly lower at the age of 48 . By contrast, the probability of over-investment in the full sample and the sample of state-owned listed companies is significantly higher at the age of 60 . The above results suggest that as an informal institutional arrangement, the cultural phenomenon of the year of fate significantly affects the investment behavior of enterprise managers.
\end{abstract}

\section{Introduction}

\subsection{Source of the topic}

The author accidentally read an article in the journal "Accounting Research", "Religious Atmosphere and Agency Conflict in Investment--An Empirical Study Based on the Number of Temples in the Listed Companies", which inspired me and it generated an extreme interest in the informal system. Moreover, the author has contacted a large number of corporate executives during the investment banking internship. It is evident that for older executives, informal institutional arrangements (such as traditional culture) have a deep imprint on their behavioral decisions.

\subsection{Background Overview}

\subsubsection{The meaning of this birth year}

The birth year is an essential cultural phenomenon in Chinese traditional culture. Based on the genus of the individual's birth, every 12 years as a cycle, the same genus is the same as the individual's birth year. In traditional customs, the birth year is often considered to be an unlucky year. The tradition of the birth year has had a huge impact on all aspects of society as a cultural environment since its inception; the influence of this tradition is more common than a specific religion.

Therefore, the author believes that the birth year as an important tradition will affect individual behavior in society as an informal institutional arrangement.

\subsubsection{Origin of informal institutional arrangements}

Previous studies have found that formal institutional arrangements can not fully explain many phenomena, so scholars have begun to focus on informal institutional arrangements. Williamson (2000) argues that informal institutional arrangements (such as religion, culture) have the same important role as formal institutional arrangements (such as law). Alleneta and Pistorand (2005) suggested that informal institutional arrangements can play a complementary role in emerging 
markets due to the lack of formal institutional arrangements. Previous studies have discussed the impact of informal institutional arrangements such as relationships, political connections, and religion on corporate decision-making behavior.

\subsubsection{Innovations in this article}

The birth year discussed in this article is between culture and religion, but as a tradition that does not belong to a specific religion, it has a more general scope of influence than religion, while existing research is the informal institutional arrangements of the custom category are also less concerned. Based on China's cultural and economic background, this paper analyzes the influence of this custom culture on the investment behavior of listed companies which helps to have a better understanding the role of informal institutional arrangements in China's economic development. The results of this paper show that private listed companies have a significantly lower probability of over-investment in their actual controller's birth year, but this phenomenon is not significant in country-owned enterprises.

\subsection{Contributions of this paper}

\subsubsection{The impact of informal institutional arrangements on corporate behavior}

This paper enriches relevant research on the impact of informal institutional arrangements on corporate behavior, especially cultural and religious aspects. Due to the limitations of the information disclosed by the management of the company, the information about the individual religious beliefs of the management is difficult to obtain. The regional variables are usually used as the proxy variables of the religious influence at the enterprise level. In this paper, the use of the birth year as a proxy variable can more specifically locate the information in the individual level and company level. In addition, the birth year is a common tradition in all regions of China and has a broader influence than religion.

\subsubsection{Research on the factors affecting investment efficiency}

This paper enriches relevant literature on investment efficiency. Previous studies have discussed the impact of formal institutions on corporate investment efficiency, such as information quality and corporate governance, from the perspective of agency theory. The discussion from the individual characteristics of managers also focuses on rational economic people and pays attention to their personal traits. This paper provides an incremental research contribution from the influence of the informal system on the individual managers, which in turn affects the investment mechanism of the enterprise.

\subsubsection{Exploring the mysteries of the informal system in China}

This paper attempts to explore the "mystery of China's economic growth" since the reform and opening up from the perspective of informal institutions. China's emerging economy has grown rapidly, and previous studies have discussed the formal institutional arrangements such as the political system to explain this miracle of growth. However, in the case that the formal system is not yet fully contribute, what role does the informal system play and what is meaning of China's special cultural background? The conclusions of this paper have explained this.

\subsection{The framework of this paper}

This paper first reviews the relevant literature conducts relevant theoretical analysis and proposes research hypotheses. Next, we introduce model building, variable definitions, and data sources. The empirical analysis of this paper includes descriptive statistics, related variable analysis and empirical results analysis. Finally, draw conclusions and explore future research directions.

\section{Literature review, theoretical analysis, and research hypothesis}

\subsection{Literature review}

\subsubsection{Phenomenon of excessive investment behavior}

Investment is an important strategic activity of the company. Usually, an efficient investment can promote the value of the company and increase the return of shareholders. However, as early as 1996, 
Meckling and Jensen wrote that in the framework of formal institutional arrangements, due to the existence of agency conflicts, operators may invest their free cash flow in some investment projects with negative net present value. Therefore, the company's investment activities deviate from the goal of maximizing shareholder value, and the supervision cost caused by information asymmetry will cause insiders to invest free cash flow in investment projects that benefit themselves rather than shareholders, thus building a "corporate empire". Help them get more on-the-job spending and other invisible incentives.

Pan Min and Jin Yan (2007) have estimated that even though China's rapid growth relies heavily on investment and accumulation, over-investment is widespread and capital investment returns are low. According to Xin Qingquan (2009), the return on capital investment of some listed companies is even lower than the cost of capital.

\subsubsection{Formal institutional reasons for excessive investment behavior}

The existing research mainly discusses this phenomenon from formal institutional arrangements such as institutional environment and property rights. For example, Cheng Zhongming and Zhang Honghui (2014) believe that the main reason is local government intervention; in addition, Yu Honghai (2016) also argues that the existence of the equity concentration and it controls shareholders.

\subsubsection{Informal institutional reasons for over-investment}

The above research is mainly discussed from the perspective of formal institutional arrangements. However, at this stage, China has a relatively late start and relatively weak system construction. In the past development process, it is different from the Western "rule-based" economic development model. It was a "relationship-based" economic development model, so Kimberand (2007) pointed out that informal institutional arrangements also affect corporate governance and business activities.

Some scholars analyzed the agency conflict and over-investment behavior of the company from the perspective of informal institutional arrangements. For example, Du Xingqiang et al. (2011) discussed the over-investment behavior of country-owned listed companies from the perspective of political connections and believed that political connections would exacerbate excessive investment behavior of country-owned listed companies and thus reduce corporate value. Duchard (2012), from a religious perspective, believed that religion helped to alleviate agency conflicts between owners and managers.

\subsubsection{Managerial level reasons for excessive investment behavior}

In addition, some scholars also discussed the influence of managerial traits on the company's excessive investment behavior from the perspective of managerial characteristics. For example, Jiang Fuxiu (2009) found that the manager's age and education were negatively correlated with the company's excessive investment behavior.

\subsection{Theoretical analysis}

\subsubsection{General theoretical research}

The above research shows that the company's investment behavior is affected by both formal and informal institutional arrangements. Culture and religion, as important informal institutional arrangements, have a significant impact on the company's investment behavior. Corporate activities are usually determined by specific corporate manager behavior, so their individual motivation and value attitudes interact with internal or external oversight mechanisms to influence their behavioral functions.

According to Iannaccone, Mille, and Weaverand (2013), culture and religion can integrate and reflect ethical issues within the company. Religious and cultural behavior can influence managers' behaviors and their expectations for the future. In particular, Barnettetal (2006) found that individuals with religious beliefs would follow a more traditional view and have a more robust and cautious code of conduct. In addition, McGuireetal (2012) proposes that religious, social norms play an important role in mitigating agency conflicts, especially when external system supervision is weak.

\subsubsection{China's special national conditions}

As the largest emerging market in China, traditional corporate governance mechanisms and low levels of investor protection, flawed regulatory environment, and low efficiency of law enforcement 
all determine that social ethics from cultural and religious levels will play an important role. Therefore, whether it is a specific religious belief or a broad belief in folklore, it will have an important impact on corporate behavior and decision-making, and in particular, will affect the decision-making process of managers.

\subsubsection{Theoretical study of irrational behavior}

Investment decisions made by managers are often made under uncertain conditions. Kahneman's (2006) study shows that under uncertain conditions, people's decisions may systematically deviate from the predictions made by traditional economic theory. Therefore, Kahneman and other scholars have questioned the rationale assumptions of human activities in certain environments. They found that in real life, decision-makers do not evaluate uncertain events according to the law of probability, and they are not always in accordance with the theory of "expected effect optimization" to make a decision.

Therefore, behavioral financiers believe that investors are not always rational, and their investment decisions are influenced by their personal beliefs and emotions. The company's investment activities often face higher uncertainties and risks than daily business activities and financing activities.

This kind of risk comes from two aspects for the manager: Firstly, the future cash flow of the investment activity has higher uncertainty, and may face the risk of investment failure, which will cause the future profit of the enterprise to decline, thus affecting the personal income of the manager; Secondly, due to the separation of company control rights and cash claim rights, managers' investment activities may deviate from the expectation function under the agency relationship, carry out opportunistic behavior and moral hazard, and investors expect managers to expect this to managers. An act may punish it, so the second risk to the manager for the investment activity is the risk of being discovered opportunistically. Therefore, company managers will judge their future risks when they face investment decision-making. This judgment process will be influenced by its personal values.

\subsubsection{Traditional culture affects Chinese investment behavior}

In the process of judging future risks, management is influenced by personal characteristic variables such as education, experience, beliefs, and values. The birth year is a kind of custom culture that has existed in various regions of China for a long time, between folk customs and religious beliefs. Unlike specific religions such as Buddhism and Taoism, this year of birth has a wider influence. In China, because of the strong integration between religion and customs, it is difficult for people to completely distinguish a certain custom into a certain kind of religion, and these traditional cultural practices are integrated into the entire Chinese traditional cultural system, collectively known as Chinese studies.

After the founding of People Republic of China, China's religious influence has been weakened for political reasons, but traditional culture is difficult to divorce from people's living habits and values. Therefore, the birth year is one of the traditions, combined with a series of traditional cultural concepts such as the genus, the lunar calendar, and the Spring Festival, forming a system with a relatively systematic custom culture. On the other hand, the concept of the birth year has a certain religious mysticism. The idea is that the external force with mysticism has an impact on people's fortune, even though Science is difficult to explain, but this traditional traditon has become an important part of Chinese cultural life through word of mouth, and it has affected people's actual actions, such as wearing red ropes and wearing red clothes. People are usually more cautious and careful in their birth year.

\subsection{Research hypothesis}

Based on the above analysis, this paper proposes the following research hypotheses.

H0: The probability of over-investment of a listed company in the actual year of the controller's life is significantly lower than that of other years.

$$
P\left(O I N V_{i t}=1\right)=\frac{1}{1+e^{-\left(\beta_{0}+\beta_{1} \text { FATE }_{i t}+\beta_{2} \text { GROWTH }_{i t}+\beta_{3} F I R S T_{i t}+\beta_{4} S I Z E_{i t}+\beta_{5} L E V_{i t}+\beta_{6} C F O_{i t}\right)}}
$$




\section{Models and data}

\subsection{Models and variables}

In order to test the above research hypothesis, that is, "in the actual control of the person's life year, the company's excessive investment probability will be significantly reduced." Based on the regression model of Jiang Fuxiu and Yi Zhihong (2009), this paper builds the following LOGIT model (1):

Table 1 Variables and definitions

\begin{tabular}{|c|c|}
\hline Variables & Definitions \\
\hline OINV & $\begin{array}{l}\text { Over-investing in dummy variables, if there is excessive investment, } \mathrm{OINV}=1 \text {, } \\
\text { otherwise OINV=0 }\end{array}$ \\
\hline FATE & $\begin{array}{l}\text { The dummy variable of this birth year, if the year is the life of the board of } \\
\text { directors, FATE=1, otherwise FATE }=0\end{array}$ \\
\hline GROWTH & $\begin{array}{l}\text { Growth = (operating income in the current year - operating income in the } \\
\text { previous year) / operating income in the previous year }\end{array}$ \\
\hline FIRST & The shareholding ratio of the largest shareholder \\
\hline SIZE & Company size, the natural logarithm of total assets at the end of the period \\
\hline LEV & Balance sheet, total liabilities / total assets \\
\hline CFO & Net cash flow from operating activities \\
\hline
\end{tabular}

In model (1), OINV represents over-investment, and POINV represents the probability of over-investment. This birth year is FATE if the actual controller of the year is the first year of life (this article is mainly based on the data, the age of $36,48,60,72$ ). If the coefficient $\beta \_1$ is significantly negative, the assumption is true.

The authors refer to the practice of Cheneter (2014) to estimate the over-investment (OINV) variable in the model (1) according to model (2) for each observation.

First, using model (2), the actual INV and other financial data for each listed company's observations for each year are regressed by industry year, and the coefficients are estimated:

$$
I N N_{i t}=\alpha_{0}+X_{i t}^{\prime} \beta+\delta_{i}+\gamma_{t}+\varepsilon_{i t}
$$

The subscript of the variable in the model (2) is the cross-sectional observation of the period $\mathrm{t}=1$, $2 \ldots \mathrm{T}, \gamma$ is the period variable effect, $\delta$ is the individual variable effect, $\alpha$ is the constant, $\varepsilon$ is the error term, and $\mathrm{X}$ is the all-argument Vector (including INV, GROWTH, FIRST, LEV, CFO). INV stands for investment efficiency $=[$ (purchasing fixed assets, cash intangible assets and other long-term assets) / total assets], GROWTH stands for growth, FIRST stands for the largest shareholder, SIZE is the company size, and LEV is the asset. The debt ratio, CFO, is the operating cash flow / total assets.

Secondly, using the previous estimation coefficients $(\alpha, \gamma, \varepsilon, \delta)$ and the actual financial data Xit, the expected investment efficiency $\mathrm{E}(\mathrm{INV})$ is estimated as follows: $\mathrm{E}($ (INV) $) \_\mathrm{it}=\alpha \_0+\mathrm{X} \mathrm{it}^{\wedge}{ }^{\prime}$ $\beta+\delta \_i+\gamma \_t+\varepsilon \_$it

Again, the residual of the actual value INV and the expected value EINV, that is, the over-investment $\Delta \mathrm{INV}=\mathrm{INV}$-EINV, is calculated. If $\Delta \mathrm{INV}>0$, there is excessive investment, $\mathrm{OINV}=1$, and $\mathrm{OINV}=0$.

\subsection{Sample selection and data sources}

This paper selects Chinese A-share listed companies for the period of 2007-2017 as the research object, mainly considering the integrity and reliability of data sources. Relevant financial and corporate governance data and executive information are from the CSMAR database, where the data of the birth year is calculated based on the age of the actual controller.

On this basis, the samples excluded from this paper include cross-listed companies, financially listed companies, ST-type companies, *ST companies, and observations of missing executive information and financial information. At the same time, in order to avoid the influence of the 
extreme values of the data, the author also carried out a $1 \%$ tail-finishing process on the continuous variables in the model to ensure the data.

\section{Empirical analysis}

\subsection{Descriptive statistics and correlation analysis}

Table 2 reports the descriptive statistics of the main variables in this paper: (1) The mean value of the interpreted variable OINV is 0.795 . It can be seen that in the sample company, nearly $80 \%$ of the observed values are over-invested. The situation of over-investment is more prominent; (2) the mean value of the explanatory variable FATE is 0.05 , indicating that about $5 \%$ of the observations in the sample are the actual controller's life years; (3) other control variables are basically the same as those of previous studies. Consistent, indicating that there is no significant problem with sample selection.

Table 2 Descriptive statistics of main variables

\begin{tabular}{ccccccc}
\hline Variable & $\begin{array}{c}\text { Number of } \\
\text { observations }\end{array}$ & Average & $\begin{array}{c}\text { Standard } \\
\text { deviation }\end{array}$ & Minimum & Median & Maximum \\
\hline OINV & 16995 & 0.795 & 0.403 & 0 & 1 & 1 \\
FATE & 16995 & 0.054 & 0.226 & 0 & 0 & 1 \\
SIZE & 16995 & 21.747 & 1.217 & 19.082 & 21.611 & 25.389 \\
LEV & 16995 & 0.493 & 0.231 & 0.054 & 0.494 & 1.375 \\
FIRST & 16995 & 0.368 & 0.156 & 0.09 & 0.347 & 0.752 \\
CFO & 16995 & 0.045 & 0.078 & -0.202 & 0.045 & 0.263 \\
GROWTH & 16995 & 0.513 & 1.987 & -0.968 & 0.102 & 16.243 \\
\hline
\end{tabular}

Table 3 reports the Pearson correlation analysis of the main variables. From the results, OINV and FATE are negatively correlated at $5 \%$, which initially supports the hypothesis of this paper. In addition, firm size and over-investment are positively correlated with over-investment at $1 \%$ level, the asset-liability ratio is negatively correlated with over-investment at $1 \%$ level, and cash flow from operating activities is negatively correlated with over-investment at $10 \%$.

Table 3 Pearson correlation analysis of main variables

\begin{tabular}{cccccccc}
\hline & OINV & FATE & SIZE & LEV & FIRST & CFO & GROWTH \\
\hline OINV & 1.0000 & & & & & & \\
FATE & $-0.0150^{* *}$ & 1.0000 & & & & & \\
SIZE & $0.0306^{* * *}$ & $-0.01520^{* *}$ & 1.0000 & & & & \\
LEV & $-0.0402^{* * *}$ & -0.0003 & $0.21915^{* * *}$ & 1.0000 & & & \\
FIRST & -0.0092 & -0.0026 & $0.25954^{* * *}$ & -0.00695 & 1.0000 & & \\
CFO & $-0.0129^{*}$ & $-0.0174^{* *}$ & $0.0599^{* * *}$ & $-0.1492^{* * *}$ & $0.0789^{* * *}$ & 1.0000 & \\
GROWTH & -0.0046 & -0.0089 & $-0.0195^{* *}$ & $0.0709^{* * *}$ & $-0.0159^{* *}$ & $-0.0826^{* * *}$ & 1.0000 \\
\hline
\end{tabular}

Note: $* * * * *, *$ represent the $1 \%, 5 \%, 10 \%$ significance level (two-tailed)

\subsection{Regression results}

Table 4 shows the regression results of over-investment and actual controllers in the full sample. (1) The results show that the over-investment and actual controllers have a life-year coefficient of -0.02 , but the statistics are not significant, and the assumptions are not supported. Considering that the four years of age $(36,48,60$, and 72$)$ are included in the birth year, we further subdivide the birth year variable into four different ages. The results in columns (3) and (4) show a significant negative correlation with the over-investment at the 5\% level for the 48-year-old natal year; a significant positive correlation with over-investment at the $1 \%$ level for the 60 -year-old birth year. There are contradictory situations in the relationship between the age of the two different ages and over-investment. 
A possible explanation for the above results is that in the column (2), due to the younger age of 36 , there may be a "learning young and frivolous" mentality, which does not pay attention to the constraints of traditional practices such as the birth year; in the column (5), due to the age of 72 years old. It is already big, and the attitude towards the birth year is already indispensable. In addition to the characteristics of the birth year, the 60-year-old in the (4) column has an important factor of reaching the "retirement age," especially in the state-owned enterprises where the actual controller faces retirement, in the last year of his own employment. Over-investment may have a mentality of "final acquisition of rent-seeking." However, the 48-year-old birth year in column (3) does not have other special circumstances related to that age, which can support the hypothesis of this paper to some extent.

In order to further verify the above-mentioned possible assumptions, we further test the above results according to the property rights attribute (only all the birth years, 48 years old and 60 years old).

Table 4 Over-investment and actual controller human life regression results (LOGIT regression)

\begin{tabular}{cccccc}
\hline \multirow{3}{*}{ Variable } & $\begin{array}{c}(1) \\
\text { AGE }=36 / 48 / 60 \\
172\end{array}$ & $\begin{array}{c}(2) \\
\text { AGE=36 }\end{array}$ & $\begin{array}{c}(3) \\
\text { AGE=48 }\end{array}$ & $\begin{array}{c}(4) \\
\text { AGE=60 }\end{array}$ & $\begin{array}{c}(5) \\
\text { AGE=72 }\end{array}$ \\
\cline { 2 - 6 } & Coefficient & Coefficient & Coefficient & Coefficient & Coefficient \\
\hline \multirow{2}{*}{ FATE } & -0.02 & $-0.47^{*}$ & $-0.18^{* *}$ & $0.35^{* * *}$ & $-0.86^{*}$ \\
& $(-0.89)$ & $(-1.23)$ & $(-0.23)$ & $(0.12)$ & $(-0.34)$ \\
SIZE & $-0.10^{* * *}$ & $-0.10^{* * *}$ & $-0.10^{* * *}$ & $-0.10^{* * *}$ & $-0.10^{* * *}$ \\
& $(-0.72)$ & $(-0.28)$ & $(-0.13)$ & $(-0.35)$ & $(-0.34)$ \\
LEV & $-0.56^{* * *}$ & $0.60^{* * *}$ & $0.56^{* * *}$ & $0.56^{* * *}$ & $0.55^{* * *}$ \\
& $(-1.21)$ & $(0.34)$ & $(0.25)$ & $(0.34)$ & $(0.13)$ \\
FIRST & $0.34^{* * *}$ & $0.34^{* * *}$ & $0.35^{* * *}$ & $0.34^{* * *}$ & $0.34^{* * *}$ \\
& $(0.33)$ & $(0.47)$ & $(0.13)$ & $(0.13)$ & $(0.17)$ \\
CFO & $0.68^{* * *}$ & $0.68^{* * *}$ & $0.67^{* * *}$ & $0.67^{* * *}$ & $0.68^{* * *}$ \\
& $(1.47)$ & $(1.13)$ & $(1.28)$ & $(1.36)$ & $(1.23)$ \\
GROWTH & 0.00 & 0.00 & 0.85 & 0.00 & 0.00 \\
& $(0.55)$ & $(0.62)$ & $(0.67)$ & $(0.53)$ & $(0.67)$ \\
Intercept & 0.33 & 0.34 & 0.31 & 0.37 & 0.33 \\
Adjusted $\mathrm{R}^{2}$ & $0.26)$ & $(0.23)$ & $(0.35)$ & $(0.23)$ & $(0.73)$ \\
\hline
\end{tabular}

Note: $* * * * *, *$ represent the significance level of $1 \%, 5 \%$, and $10 \%$, respectively (two-tailed); the $t$ value of the estimated coefficient in parentheses

The results in Table 5 show that in column (1), the over-investment of the company under private enterprises is significantly negatively correlated with the actual controller's life expectancy at $5 \%$, while the relationship among country-owned enterprises is not significant, indicating that the factor of birth year is in private enterprises. It has a restrictive effect on excessive investment by enterprises, but this effect is not significant in country-owned enterprises. In column (2), the 48-year-old birth year also achieved the same result, which was significantly negatively correlated at the $5 \%$ level in the private enterprise sample, while the relationship was not significant in the state-owned enterprise sample.

In addition, we have mentioned above that the assumption that the 60 -year-old birth year may involve retirement age is also supported. In the (3) column, the 60-year-old birth year is significantly positively correlated with over-investment at the $1 \%$ level in state-owned enterprises. The relationship is not significant in private enterprises.

A possible explanation for the above results is that the actual controllers in private enterprises usually have higher decision-making power (as controlling shareholders), while the actual controllers in state-owned enterprises are usually officials appointed by the government and concurrently in administrative positions. At the same time, the actual controller's personal wealth in private enterprises is more closely related to the consequences of an investment, and more attention is paid to the "bad luck" that may be brought about by this birth year. However, there is no problem with actual 
controller retirement in private enterprises. The 60 -year-old effect is not significant in private enterprises, but this is the case in state-owned enterprises. The test results also support this view.

Table 5: Over-investment and actual control of human life-year regression results under different property rights attributes (LOGIT regression)

\begin{tabular}{|c|c|c|c|c|c|}
\hline Variable & $\begin{array}{c}1) \\
A G E=36 / 48 / 60 \\
/ 72\end{array}$ & $\begin{array}{c}(2) \\
A G E=36\end{array}$ & $\begin{array}{c}(3) \\
A G E=48\end{array}$ & $\begin{array}{c}(4) \\
A G E=60\end{array}$ & $\begin{array}{c}(5) \\
A G E=72\end{array}$ \\
\hline & Coefficient & Coefficient & Coefficient & Coefficient & Coefficient \\
\hline FATE & $\begin{array}{c}-0.02 \\
(-0.89)\end{array}$ & $\begin{array}{l}-0.47^{*} \\
(-123)\end{array}$ & $\begin{array}{l}-0.18^{\star *} \\
(-023)\end{array}$ & $\begin{array}{l}0.35^{\star * *} \\
(012)\end{array}$ & $\begin{array}{l}-0.86^{*} \\
(-0.34)\end{array}$ \\
\hline SIZE & $\begin{array}{l}-0.10^{* \star *} \\
(-0.72)\end{array}$ & $\begin{array}{l}-0.10^{* * *} \\
(-0.28)\end{array}$ & $\begin{array}{l}-0.10^{* \star *} \\
(-0.13)\end{array}$ & $\begin{array}{l}-0.10^{\star \star \star} \\
(-0.35)\end{array}$ & $\begin{array}{l}-0.10^{* * *} \\
(-0.34)\end{array}$ \\
\hline LEV & $\begin{array}{l}-0.56^{\star \star *} \\
(-1.21)\end{array}$ & $\begin{array}{l}0.60^{* * *} \\
(0.34)\end{array}$ & $\begin{array}{l}0.56^{* * *} \\
(0.25)\end{array}$ & $\begin{array}{l}0.56^{* * *} \\
(0.34)\end{array}$ & $\begin{array}{l}0.55^{\star * *} \\
(0.13)\end{array}$ \\
\hline FIRST & $\begin{array}{l}0.34^{* * *} \\
(0.33)\end{array}$ & $\begin{array}{l}0.34^{* * *} \\
(0.47)\end{array}$ & $\begin{array}{l}0.35^{\star \star *} \\
(0.13)\end{array}$ & $\begin{array}{l}0.34^{* * *} \\
(0.13)\end{array}$ & $\begin{array}{l}0.34^{* * *} \\
(0.17)\end{array}$ \\
\hline CFO & $\begin{array}{l}0.68^{* * *} \\
(1.47)\end{array}$ & $\begin{array}{l}0.68^{* * *} \\
(1.13)\end{array}$ & $\begin{array}{l}0.67^{* * *} \\
(1.28)\end{array}$ & $\begin{array}{l}0.67^{* \star *} \\
(1.36)\end{array}$ & $\begin{array}{l}0.68^{\star * *} \\
(1.23)\end{array}$ \\
\hline GROWTH & $\begin{array}{c}0.00 \\
(0.55)\end{array}$ & $\begin{array}{c}0.00 \\
(0.62)\end{array}$ & $\begin{array}{c}0.85 \\
(0.67)\end{array}$ & $\begin{array}{c}0.00 \\
(0.53)\end{array}$ & $\begin{array}{c}0.00 \\
(0.67)\end{array}$ \\
\hline Interpret & $\begin{array}{c}0.33 \\
(0.26)\end{array}$ & $\begin{array}{c}0.34 \\
(0.23)\end{array}$ & $\begin{array}{c}0.31 \\
(0.35)\end{array}$ & $\begin{array}{c}0.37 \\
(0.23)\end{array}$ & $\begin{array}{c}0.33 \\
(0.73)\end{array}$ \\
\hline Adjusted $\mathrm{R}^{2}$ & 0.13 & 0.12 & 0.12 & 0.11 & 0.12 \\
\hline
\end{tabular}

Note: $* * * * * *$ represent the significance level of $1 \%, 5 \%$, and $10 \%$, respectively (two-tailed); the $t$ value of the estimated coefficient in parentheses

\section{Conclusions and prospects}

\subsection{Conclusion of this paper}

Through empirical research, the author finds that in private listed companies, the probability of over-investment in the actual controller of the year is significantly lower, while this relationship is not significant in state-owned listed companies. Further, the probability of over-investment in the sample of full-sample and private listed companies is significantly lower at the age of 48, and the probability of over-investment in the sample of full-sample and state-owned listed companies is significantly higher at the age of 60 .

The results of this paper show that the folk culture and religious beliefs in Chinese traditional culture play a non-institutional arrangement in China's economic growth. The company's excessive investment in the year of the year is significantly reduced, which means that this cultural custom does affect business management. The behavior mode of the layer.

Different from religion, this birth year has a wider influence as a custom. At the same time, because this birth year is a relatively clean exogenous variable, it can be used as a breakthrough point for a culture to image the corporate behavior. The above research conclusions help us understand that China, as the largest emerging economy, has played an important complementary role in the rapid growth of informal institutional arrangements due to the imperfect formal institutional arrangements.

\subsection{Limitations and Prospects of this Paper}

The research in this paper still has certain limitations, mainly reflected in the following aspects. First of all, the data of the birth year of this paper adopts the age disclosed in the CSMAR database. Because the age is usually calculated by the Gregorian calendar, and the birth year is mainly calculated by the lunar calendar, the two may have errors, which also restricts the accuracy of this paper. Secondly, this paper only considers the influence of the actual controller's life-year. CFO may also play an important role in specific investment matters. The impact of other managers' life-years on over-investment needs further study. Finally, this article does not consider the factors affecting the 
relationship between the birth year and the excessive investment, such as higher education or party membership, which may weaken this effect. The future needs to be further tested by constructing the intersection term.

\subsection{Inspiration from the article}

In the real world of corporate governance, informal institutional arrangements have a positive effect on social development. One problem that needs to be actively faced today is that we need to carefully examine the role of the informal system in social development and market operations in a relatively weak institutional environment, and take the essence to abandon its dross. Informal institutions such as customs, culture, and religion constitute the basic rules of social operation. Due to the incompleteness of the formal contract, it is impossible for a formal system to establish social rules without any detail. Even in a developed formal institutional environment, social operations still need to rely on informal systems to maintain and lubricate.

This paper is inspired by research in the field of corporate finance. In addition to the study of the role of formal institutions, it is necessary to pay attention to the corporate governance role of informal institutions in the organization of people. The author's policy makers and regulators should be aware of the important subsidiary role of the informal system in regulating social relations. When the formal system fails to function properly, the informal system often acts as a society that reduces the relatively weak formal contract from the perspective of running costs.

\section{References}

[1] Barnettetal Bass. Religiosity, Ethical Ideology, and Intention Store Porta Peer's Wrong Doing[J]. Journal of Business Ethics, 2006,15(11): 1161-1175.

[2] Kahneman M.C. Agency Costs and Free Cash Flow, Corporate Finance, and Take Overs[J]. American Economics Reviews. 2006,76(1): 659-665.

[3] Alleneta J., Chenetal L., Pistorand Daniel. Do Culture and Religion Mitigate Earnings Management? Evidence from Across Country Analysis[J]. International Journal of Disclosure and Governance. 2005,8(1): 103-121.

[4] Kimberand S.J. Business Ethics and Religion: Religiosity as a Predict or of Ethical Awareness among Students[J]. Journal of Business Ethics. 2007,50(2): 383-396.

[5] Meckling Jasper, Jensen S. Sun. Corporate Governance and Social Responsibility: Combating Money Laundering in the Asia Pacific Region[J]. Contemporary Studies in Economic \& Financial Analysis, 1996,86(2): 435-452.

[6] Williamson, R.M. Financial Accounting Information and Corporate Governance[J]. Communication of Finance \& Accounting. 2000,6(1): 57-61.

[7] McGuireetal R. Introduction to the Economics of Religion[J]. Journal of Economic Literature. 2012,36(1): 146-149.

[8] Mille S., Iannaccone L.R., Weaverand S. Government Intervention and Investment Efficiency: Evidence from China[J]. Journal of Corporate Finance. 2013,17(2): 259.

[9] Duchard O. Thomas. Geographic Earnings Disclosure and Trading Volume[J]. Social Science Electronic Publishing. 2012,28(3): 167-188. 